\title{
Exploring Students' Product Design Concept Generation and Development Practices
}

\section{Mr. Jin Woo Lee, University of Michigan}

Jin Woo Lee is a PhD student in Mechanical Engineering at the University of Michigan.

\section{Dr. Shanna R. Daly, University of Michigan}

Shanna Daly is an Assistant Professor in Mechanical Engineering at the University of Michigan. She has a B.E. in Chemical Engineering from the University of Dayton (2003) and a Ph.D. in Engineering Education from Purdue University (2008). Her research focuses on strategies for design innovations through divergent and convergent thinking as well as through deep needs and community assessments using design ethnography, and translating those strategies to design tools and education. She teaches design and entrepreneurship courses at the undergraduate and graduate levels, focusing on front-end design processes.

\section{Mr. Varghese Ittoop Vadakumcherry, University of Michigan}

Varghese Vadakumcherry is a senior at the University of Michigan, currently pursuing a degree in Mechanical Engineering. He has a great interest in Design Science and is currently working with Dr. Shanna Daly in developing methods conducive to the design process, particularly in the early stages of concept generation and selection. 


\section{Exploring Students' Product Design Concept Generation and Development Practices}

Engineers are challenged with addressing open-ended design problems; successful innovation often hinges on the generation of creative concepts during early stage ideation and the ability to iterate on those concepts to develop final designs. To explore students' approaches to concept generation and development, we conducted a multiple phase think-aloud and interview study to uncover current student practices and explore the impact of a specific instructional approachlearning blocks, which combine online learning with one-on-one coaching sessions to provide feedback to students — on students' ability to incorporate best practices in their idea generation and development approaches. In this paper, we describe the practices of three student participants to provide in-depth understanding of students with different educational levels. These three participants demonstrated a range of approaches to idea generation and development in their pre-instructional sessions, such as generating a limited number of ideas and searching for existing ideas. After completing the learning blocks, all students showed progress, including minimizing evaluating their initial ideas, which led to an increase of ideas generated and developed. Furthermore, students were equipped with ideation techniques that helped them explore the solution space and come up with ideas in a systematic manner. This study reveals challenges students have in idea generation and development and the impact that instruction can have on their incorporation of best practices.

\section{Introduction}

To solve major challenges of the $21^{\text {st }}$ century, engineers must be prepared to use design principles that lead to innovative solutions [1]. ABET also emphasizes the importance of training undergraduate engineering students to develop design skills [2]. In a design process, idea generation and development are important steps that contribute to the innovative design outcomes [3]. However, research indicates challenges for students in generating creative concepts for open-ended design problems [4].

Successful implementations of creative ideas can lead to innovation. Ideally, idea generation and development stages would provide opportunities to explore a variety of different, creative ideas [5] that would serve as the foundation for synthesizing the final solution. However, engineers often do not consider multiple, creative designs and they become focused on variations of existing ideas [6] or attached to specific ideas early on, a term called fixation [7]. These behaviors can limit the exploration of possible concepts and minimize the diversity of concepts generated [4]. When engineers navigate idea generation and development, the structure and method of coming up with ideas is unclear. Furthermore, instruction on concept generation and development is not offered in engineering classes. When ideation is taught, it is commonly through techniques like brainstorming, which can lack structure and may not provide specific ways to guide idea generation and development [8].

This study used think-aloud and interviews to analyze how engineering students explore potential solutions and further develop design concepts to address open-ended problems. In addition to capturing their natural idea generation and development practices, we studied the 
impacts of recently developed learning blocks that combine online learning composed of best design practices with one-on-one coaching sessions on student approaches to idea generation and development.

\section{Background}

The literature points out misconceptions and behaviors in idea generation of novice engineers [9]. Novice designers have difficulty considering multiple ideas during idea generation [4]. They often become fixated on a particular concept or type of concept and limit the solution exploration process [7], [10]. Some reasons for fixation include holding false assumptions, having incomplete information, and feeling overwhelmed [11]. Designers are often not aware of design fixation [12] and they can be attached to concepts with major flaws [6]. Furthermore, students often lack the skills and strategies to help them generate varying concepts [4]. When novice engineers create multiple concepts, they are often minor variations of the same ideas, which limit the potential ideas they can explore [6]. To encourage novice designers to expand the solution space, idea generation and development tools, such as TRIZ [13], Design Heuristics [14-17], Brainstorming [18], Design by analogy [19], have been implemented in classrooms to support exploration of the solution space (See Table 1 for example tools).

Table 1. Example idea generation and development tools

\begin{tabular}{|l|l|}
\hline Technique & Description \\
\hline Brainstorming & $\begin{array}{l}\text { Emphasizing generating ideas without judgement and building } \\
\text { upon ideas [18] }\end{array}$ \\
\hline Design by analogy & Using distant-domain analogies to inspire ideas [19] \\
\hline Design Heuristics & $\begin{array}{l}\text { Using concept modifiers that quickly lead to a potential solution } \\
\text { [20] }\end{array}$ \\
\hline Lateral thinking & $\begin{array}{l}\text { Generating radical statements about the problem or solution to } \\
\text { push designers to think of non-obvious ideas [21] }\end{array}$ \\
\hline Morphological analysis & $\begin{array}{l}\text { Listing attributes of a design solution and several options for each } \\
\text { attribute, then combine various attributes to generate concepts [22] }\end{array}$ \\
\hline SCAMPER & $\begin{array}{l}\text { Transforming existing concepts using these guidance: Substitute, } \\
\text { combine, adapt, modify, put to other purposes, eliminate, } \\
\text { rearrange [23] }\end{array}$ \\
\hline TRIZ & $\begin{array}{l}\text { Applying modifications to overcome contradictions in concepts } \\
\text { [13] }\end{array}$ \\
\hline
\end{tabular}

The literature further discusses misconceptions and behaviors in idea development of novice engineers. During the concept development phase, individuals must decide which ideas to develop or filter by assessing the potential of their ideas [24]. Some beginning designers spend too much time developing a single idea, which doesn't leave much time to consider other options [25]. Novice designers can approach idea development with minimal iterations [26] and often view design as a linear process that can be done once [9]. Also, students can favor more conventional ideas and filter out novel ideas early in the process [27]. 
Teaching idea generation and development to encourage creativity in thinking is often a challenge for educators [28]. To aid educators, concept generation and development learning blocks were developed. They are some of the many topics included in the learning block educational resources at the Center for Socially Engaged Design at a Midwestern university. To promote design skills, the Center for Socially Engaged Design was created to provide independent learning opportunities through on-demand online learning platforms coupled with one-on-one coaching sessions with experienced designers. Each learning block is divided into 5 sections (Figure 1): 1) Prior Knowledge Review gauges students' familiarity and existing knowledge on a topic. 2) Core Content offers best practices on a given topic through readings and videos. 3) Knowledge Check provides an opportunity to review the key materials through closed- and open-ended questions. 4) Application requires students to apply new design tools on solving an open-ended problem and meet with a coach to receive personalized feedback. 5) Reflection allows students to think about how their pre-existing ideas about a topic have evolved and expanded through completing the learning block. In this study, we examined the impact of the "Idea Generation" and "Concept Development" learning blocks. Each learning block takes approximately 6 hours to complete and is built on pedagogical best practices that combines selfstudy with remote feedback [29]. It focuses on a student-centered teaching approach developed around the constructivist learning theory [30], which allows content sharing online without time and location limitations [31]. The learning blocks are built around the best practices in teaching and learning to promote active engagement, which is essential for success [32], [33]. Studies on active learning demonstrate numerous positive impacts on students' depth and retention of knowledge [32], [33]. The learning block model combines the scalability of online education and the value of engagement through one-on-one interaction.

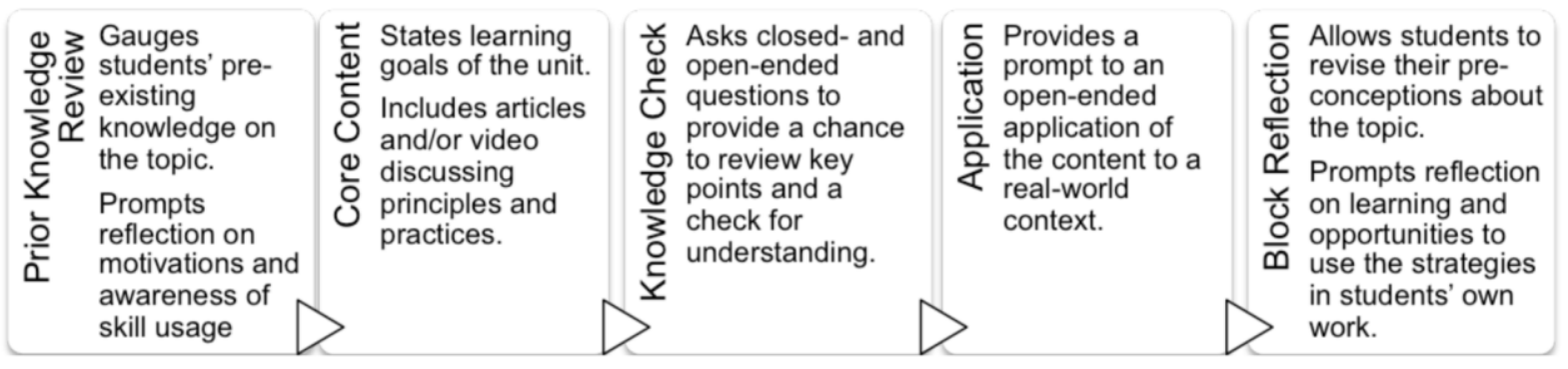

Figure 1. Center for Socially Engaged Design Learning Block Model

\section{Method}

\section{$\underline{\text { Research Questions }}$}

The focus of this study was to investigate three students' idea generation and development practices in-depth. We were interested in students' initial ideation process and how they refined their concepts. Our project was guided by the following research questions:

- How do mechanical engineering students approach idea generation and development?

- How do the Center for Socially Engaged Design learning blocks impact students' idea generation and development practices? 


\section{$\underline{\text { Participants }}$}

Participants were recruited through targeted emails to undergraduate mechanical engineering students at a large Midwestern university. In the paper presented here, we describe the experiences of three undergraduate mechanical engineering students who completed the study (Table 2). These participants were chosen based on quality of their think-aloud and interview data, demonstrating a range of elaboration during the design tasks. Also, the three participants represented a range of educational level. All three participants have taken at least one design course and indicated that they have had "little experience" or "some experience" in concept generation and development. The study protocol was approved by the University's Institutional Review Board. Participation was voluntary, and they were compensated 200 USD for approximately 18 hours of their time.

Table 2. Participants' demographics.

\begin{tabular}{|l|l|l|l|}
\hline Pseudonym & Gender & Ethnicity & Grade \\
\hline Andrea & F & Asian & Senior \\
\hline Brian & M & White & Sophomore \\
\hline Cathy & F & White & Junior \\
\hline
\end{tabular}

\section{Data Collection}

This study was broken down into three sections. Students first came into complete a preblock design task to demonstrate their natural idea generation and develop practices. Then they completed the Center for Socially Engaged Design learning blocks. Finally, students came back to complete a post-block design task, which helped us to document the changes in their idea generation and development practices (Figure 2).

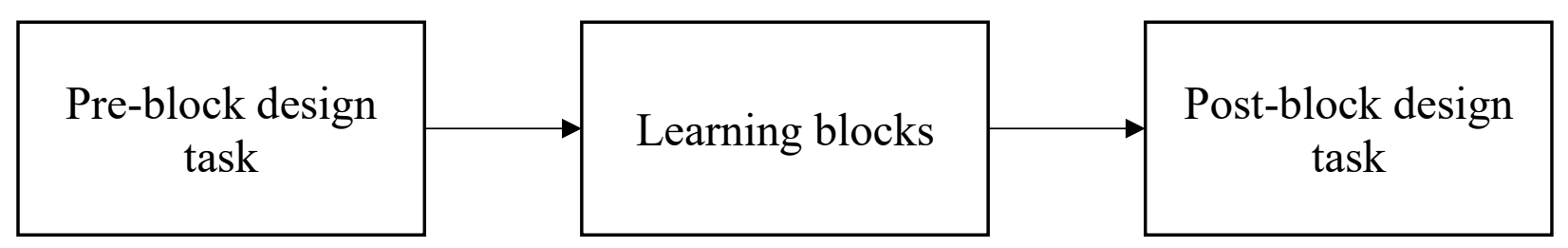

Figure 2. Progression of this study to examine students' idea generation and development practices.

In the beginning of the study, each participant completed a pre-block task that we developed to understand the baseline practices of students' concept generation and development [34]. Two pilot studies were conducted to ensure clarity of the design task. The pilot studies helped in deciding two design problems used for this study. Design problems for this study needed to be easily understood by students regardless of their background and expertise, openended to support divergence in solution exploration, and product-oriented in exploring solutions. After the pilot studies, we decided to use two design tasks (Appendix A1), which have been used in other studies [35], [36]: 1) The low-skill snow transporter problem that prompted them to design a way for individuals without much skill and experience skiing or snowboarding to 
transport themselves on snow. 2) The one-hand opener for lidded food containers problem that asked them to design a way for individuals who have limited or no use of one upper extremity to open a lidded food container.

Each participant was asked to develop solutions for the design problem and select a final solution at the end. Participants could spend as long as they needed to complete the task, but were instructed to spend a minimum of 1 hour, using any resources needed. Participants were asked to think-aloud during the session and their writing and verbalized thoughts were recorded using a Livescribe Echo pen. The think-aloud method asks participants to verbalize their thought processes during a problem solving task [37]. Compared to interviews, which require participants to explain past events and may have incomplete information, think-aloud is a direct method to gain insight in the knowledge and processes of human problem solving.

After completing the task, participants were interviewed following a semi-structured interview protocol. Andrea's, Brian's, and Cathy's interviews lasted 30, 45, and 20 minutes, respectively. Although we used the same interview protocol, the length of interviews varied on the level of elaboration in discussing their idea generation and development processes. Interviews allow exploring perceptions and opinions of the participants and enabled probing for more information [38]. Probing can be a valuable tool in ensuring reliability of the data because it allows for clarification of responses [39] and gain more complete information [40], [41]. The interview questions were developed through multiple iterations. Open-ended questions were constructed to understand students' idea generation and development practices [42] and questions were framed neutrally to avoid expressing personal opinions and leading interviewees [43] (See Table 3). Before the data collection, one pilot test was conducted to test the protocol and ensure clarity of questions being asked. One interviewer, a graduate student who was trained and has previously completed research studies in qualitative methods of research, conducted all interviews for consistency and they were audio-recorded for analysis.

Table 3. Examples of open-ended interview questions used.

\begin{tabular}{|l|l|}
\hline Interview Focus Area & Example Question \\
\hline Overview & $\begin{array}{l}\text { Can you walk me through how you developed solutions and } \\
\text { selected a final one at the end? }\end{array}$ \\
\hline Idea Generation & How did you generate ideas to address the problem? \\
\hline Idea Development & How, if at all, did you iterate on any of your ideas? \\
\hline Definition & In summary, what is idea generation in your own words? \\
\hline
\end{tabular}

Next, students were instructed to go through the "Idea Generation," "Concept Development," and "Concept Selection" learning blocks that have been developed by the Center for Socially Engaged Design. Although participants were instructed to go through all three blocks, the focus of this research was on students' understanding and misconceptions of concept generation and development. Each block was developed from combining best practices in design processes from academic literature and textbooks into text and short videos. The learning objectives of each block are shown in Figure 3. 


\begin{tabular}{|c|c|c|c|c|c|}
\hline 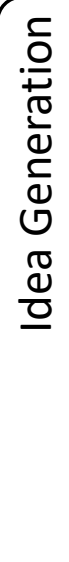 & $\begin{array}{l}\text { - Use concept generation } \\
\text { in a design process } \\
\text { - Be cognizant of the type } \\
\text { of thinking needed to } \\
\text { conduct idea generation } \\
\text { - Explore the solution } \\
\text { space using different } \\
\text { ideation techniques } \\
\text {-Recognize challenges in } \\
\text { generating ideas }\end{array}$ & 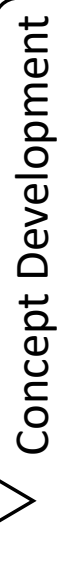 & $\begin{array}{l}\text { - Iterate on the ideas } \\
\text { from the idea generation } \\
\text { process } \\
\text { - Understand how to } \\
\text { become more effective in } \\
\text { ideating different } \\
\text { solutions } \\
\text { - Focus on drawing out } \\
\text { quality and novelty in } \\
\text { design solutions } \\
\text { - Apply a wide vareity of } \\
\text { methods to generate a } \\
\text { large quanity of concepts }\end{array}$ & 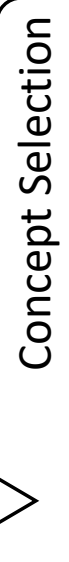 & $\begin{array}{l}\text { - Organize and filter } \\
\text { through potential } \\
\text { solutions in a meaningful } \\
\text { way } \\
\text { - Objectively compare } \\
\text { solution concepts against } \\
\text { a need specification to } \\
\text { determine what concepts } \\
\text { to pursue } \\
\text { - Apply an approach, such } \\
\text { as the Pugh method, to } \\
\text { develop a decision matrix } \\
\text { to evaluate and select } \\
\text { concepts. }\end{array}$ \\
\hline
\end{tabular}

Figure 3. The learning goals of "Idea Generation," "Concept Development," and "Concept Selection" blocks.

Once students completed the three learning blocks, they came back to complete a posttask, which was a different problem than their pre-task (Appendix A1). The students who worked on the low-skill snow transporter problem for their pre-task were given the one-hand opener for lidded food containers problem for their post-task, and vice versa. Again, participants were instructed to spend a minimum of 1 hour to complete the task, and they could use any resources during the task. Participants verbalized their thoughts through think-aloud and the session was recorded using a Livescribe Echo pen. After completing the post-task, participants were interviewed following a semi-structural format, with the beginning identical to the pre-task interviews, and a few more questions at the end were added to ask about their learning block experience. Andrea's, Brian's, and Cathy's interviews lasted 40, 35, and 35 minutes, respectively.

\section{Data Analysis}

We transcribed think-aloud sessions and interviews through a transcription service, and they were examined by an editor who listened to each think-aloud and interview session, and corrected any errors in the transcription. We used a combination of inductive and deductive coding approaches [44]. Deductive codes were developed from leveraging previously documented practices in idea generation and development such as being fixated on solutions, having few ideas generated, and using existing solutions (See Table 4 for example codes). We chose this approach to contextualize our findings with previously studied novice practices. Additional inductive codes were developed by two coders who read through the interview transcripts multiple times. The coders captured recurring trends and patterns to identify gaps in the data that were not captured by the deductive codes. Once a codebook had been developed, a third coder, in addition to one of the two originals, independently coded all the interviews and think-aloud sessions (See Appendix A2 for all the codes). An inter-rater reliability (agreement or disagreement among coders) was calculated as $74 \%$ among all pre- and post-task transcripts. Values greater than $70 \%$ are typically acceptable for inter-rater reliability [45]. The coders discussed remaining discrepancies and reached full agreement prior to finalizing the findings. 
Table 4. Example codes

\begin{tabular}{|l|l|}
\hline Code & Definition \\
\hline $\begin{array}{l}\text { Considered multiple ideas } \\
\text { (scarcity vs. fluency) }\end{array}$ & $\begin{array}{l}\text { A student considered less than 5 ideas (score 0), 5 but } \\
\text { less than 10 (score 1), 10 or greater (score 2) }\end{array}$ \\
\hline Thought of existing solutions & $\begin{array}{l}\text { Students thought or searched for existing products to } \\
\text { generate ideas }\end{array}$ \\
\hline Idea fixation & Students are attached to a single idea or similar ideas \\
\hline $\begin{array}{l}\text { Self - limiting behavior: a } \\
\text { solution is not feasible or } \\
\text { practical }\end{array}$ & $\begin{array}{l}\text { Students limited the solution space by placing } \\
\text { practicality and feasibility as a filter during idea } \\
\text { generation }\end{array}$ \\
\hline Iterated and combined ideas & $\begin{array}{l}\text { A student iterated less than 5 ideas (score 0), 5 but less } \\
\text { than 10 (score 1), 10 or greater (score 2) }\end{array}$ \\
\hline
\end{tabular}

\section{Results}

In the following section, we describe the initial approaches of three study participants and the shifts in their approaches after completing the learning blocks.

Pre-Learning Block Natural Idea Generation and Development Approaches

Participants generated and developed a varying number of ideas during the pre-learning block task using their natural approaches of ideation (Table 5). Among three participants, the number of ideas generated and developed ranged from 4 to 11 ideas.

Table 5. Participants' number of ideas generated and developed before learning blocks

\begin{tabular}{|l|l|}
\hline Pseudonym & $\begin{array}{l}\text { \# of ideas } \\
\text { generated/developed } \\
\text { before learning blocks }\end{array}$ \\
\hline Andrea & 4 \\
\hline Brian & 11 \\
\hline Cathy & 6 \\
\hline
\end{tabular}

In addition to looking at the number of ideas generated and developed, we analyzed the process of synthesizing with ideas. In the beginning, students initially used the stated constraints from the problem statement as a guide and often assumed additional requirements that were not explicitly described in the problem statement. For example, Cathy was tasked with the low-skill snow transporter problem that asked her to design a personal tool for transportation on snow. The problem statement asked her to consider solutions that allowed the user to control direction and braking but Cathy made an additional assumption that further constrained her early in the idea generation process:

"I guess, 'Direction and braking,' would imply that this should be motorized" (Cathy). 
By restricting the solution space to snow transportations that are motorized, Cathy limited the ideas that she considered during the initial idea generation and development. Because of her assumed requirement to have motors, many of her ideas fixated on having a motor to power the snow transportation (Figure 4). Concept (a) is a motorcycle-style snow transporter with snow treads (Figure 4.a). Concept (b) is an all-terrain vehicle with snow tires (Figure 4.b). Concept (c) is a snowmobile (Figure 4.c). An assumed requirement to have a motorized snow transport limited the potential solutions that she considered during the design task.

(a)

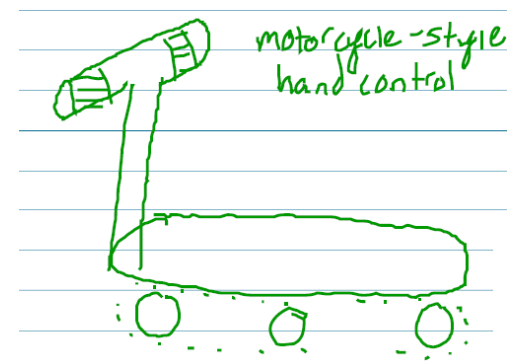

(b)

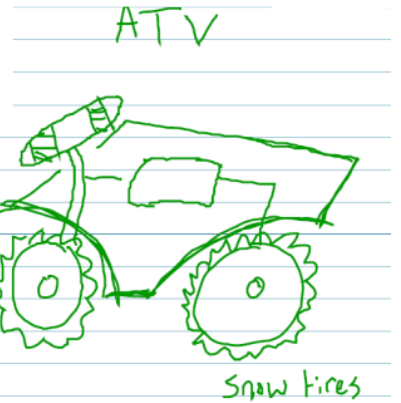

(c)

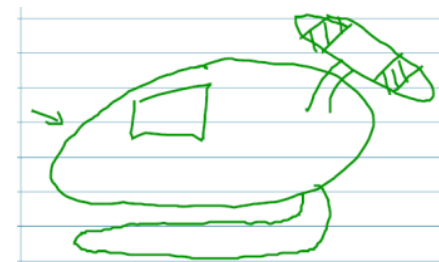

Figure 4. Examples of Cathy's initial ideas on low-skill snow transportation: (a) motorcycle with snow treads, (b) all-terrain vehicle with snow tires, and (c) snowmobile.

In addition to assuming requirements, students focused on coming up with variations of existing ideas. Andrea was tasked with solving the one-hand opener problem and she focused on looking for designs from the Internet:

"I Googled one hand opener to see if there [were] any off-the-shelf products that [are] out there. And I found some, and I borrowed some ideas from like current products, that [are] like online" (Andrea).

From searching through the Internet, Andrea found designs that would be used to open cans and bottles, and created variations of existing solutions (Figure 5). Concept (a) is similar to a bottle opener with a spring to hold down the bottle (Figure 5.a) Concept (b) is a can opener to cut open the lid and a suction cup to hold down the can (Figure 5.b).

(a)

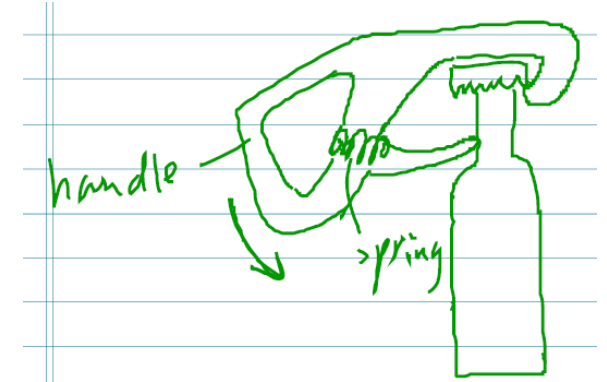

(b)

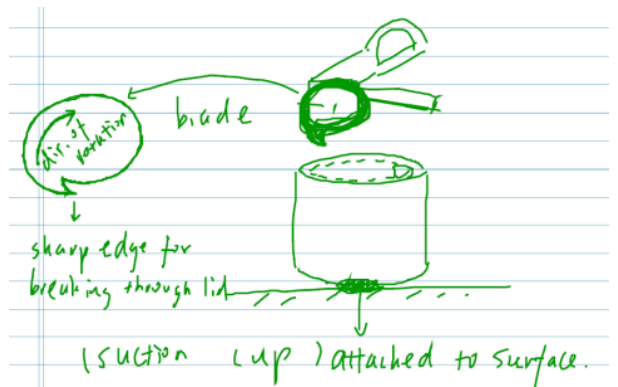

Figure 5. Examples of Andrea's ideas. (a) Bottle opener, and (b) can opener with a suction cup. 


\section{$\underline{\text { Post-Learning Block Idea Generation and Development Approaches }}$}

After participants went through the learning blocks, we observed differences in their behavior of approaching idea generation and development among the initial three participants in this study. The learning blocks encouraged students to adopt best practices in idea generation including focusing on quantity over quality of ideas. All participants at least tripled the number of ideas generated (Table 6).

Table 6. Participants' number of ideas generated and developed after learning blocks

\begin{tabular}{|l|l|}
\hline Pseudonym & $\begin{array}{l}\text { \# of ideas } \\
\text { generated/developed } \\
\text { after learning } \\
\text { blocks }\end{array}$ \\
\hline Andrea & 15 \\
\hline Brian & 34 \\
\hline Cathy & 25 \\
\hline
\end{tabular}

Students adopted specific strategies to come up with a large number of ideas. First, all participants minimized early evaluation of ideas that helped them come up with ideas without focusing on practicality of ideas:

"The biggest takeaway for me is that, previously, I tend to judge the ideas while generating ideas. But then, I learned that it's not necessary to do it, or you shouldn't do it at all, because the purpose of idea generation is to get a quantity instead of judging the quality of ideas" (Andrea).

To focus on creating a large quantity of ideas, all students started with a target number of ideas they wanted to generate:

"All right, so I'm gonna start with idea generation. I want to come up with ten ideas in this section" (Cathy).

By having a goal number, students continued to generate ideas with minimal evaluation of their initial ideas. As students generated more ideas, they typically started with variations of existing ideas. When students exhausted their initial ideas, they would consider wild and not practical ideas. For the post-task, Cathy was tasked with designing a one-handed jar openers and she wanted to come up with a different idea for her seventh idea:

"What is the coolest way you could open a jar? Well, my go-to answer for that is to smash it, and I'm not supposed to limit myself during idea generation, something tells me that smashing it isn't a good idea. Maybe if it was a controlled smash. Is there a way to control [it]... can you puncture a jar without getting stuff in your food... Now, we are going to just cut the top off (Figure 6)" (Cathy). 


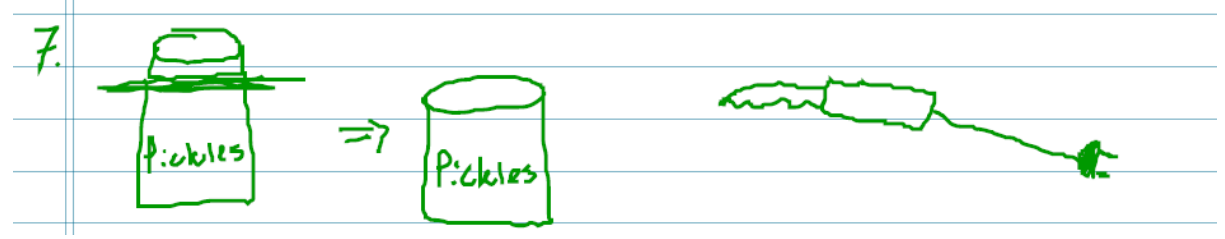

Figure 6. Cathy's idea to cut open the top of a jar with a knife.

In addition to setting a goal for the number of ideas they wanted to generate, participants used idea generation and development tools, such as Design Heuristics, Mind Mapping, Brainstorming, and Functional Decomposition, to expand the pool of ideas. Students explicitly used at least one ideation technique in the beginning of the post-task. For example, Brian worked on the low-skilled snow transporter problem for his post-task and created a mind map based on four different categories that he created: 1) power, 2) control direction, 3) braking, and 4) snow interaction (Figure 7). He then created ideas that might fit in each category. For example, to control braking, he thought of using friction, heat, or body movements.

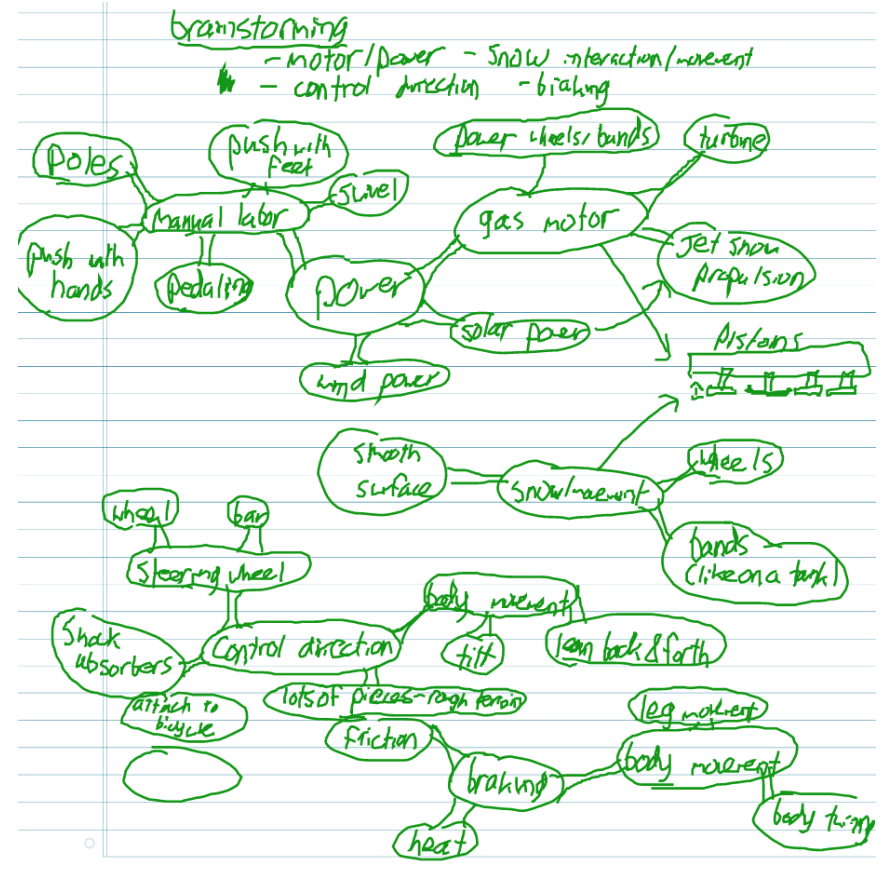

Figure 7. Brian's mind map with ideas based on different categories

After breaking down the design of a snow transporter into multiple categories and coming up with multiple ideas for each category using a mind map, Brian combined different categories to create ideas (Figure 8). Concept (a) is a snow transporter with two skis on either sides with legs coming out through the middle. It uses leg movements for braking and leaning in different directions for steering (Figure 8.a). Concept (b) has a sail to capture wind power to propel forward. The user would control direction by turning the sail and brakes by moving the sail away from the wind (Figure 8.b). Concept (c) is a jet ski on snow (Figure 8.c). By starting 
with a mind map and considering different categories to create ideas, Brian was able to generate varying concepts.

(a)

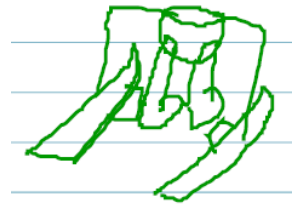

(b)

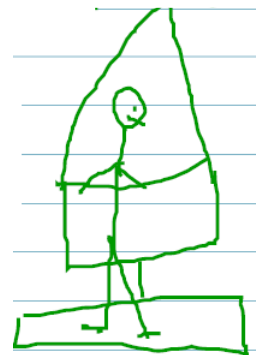

(c)

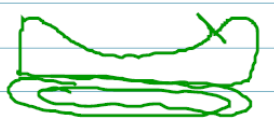

Figure 8. Examples of Brian's ideas. (a) Two skis on either side with a seat in the middle, (b) snow sail, and (c) snow jet ski.

At the end of the post-task, we asked for overall feedback of the learning block experience. Students indicated that they approached the idea generation and development processes in a systematic way and the lessons from the learning blocks provided the necessary structure:

"I really liked the structured approach to, again, generating ideas. I thought that it was more suited to me personally than just throwing out things left and right that just popped up into my head. I liked having a more structured approach to it" (Cathy).

Overall, participants gained valuable design skills from the "Idea Generation" and "Concept Development" learning blocks and they have adopted several best practices in idea generation; participants minimized the idea evaluation during the early stages, generated more ideas compared to the pre-learning block task, and used idea generation tools.

\section{Discussion}

Our analysis identified some misconceptions of initial idea generation and development for engineering students. They often started to approach an open-ended problem by having assumed requirements, which led to being fixated on a specific function of a device that was perceived as an important need. For example, Cathy came up with an assumed requirement to create a motorized transportation method on snow. This aligns with previous studies describing fixation due to false assumptions [11].

All students approached initial idea generation without a clear structure and did not explicitly use design strategies to help them consider a wide variety of options. Instead, students focused on coming up with variations of existing solutions [6] and developing ideas that were practical and feasible.

After going through the learning blocks, students' approached idea generation and development with clear aims and strategies. All students at least tripled the number of initial ideas they generated and developed. Andrea, Brian, and Cathy generated 4, 11, and 6 ideas 
during pre-task and they increased the number of ideas to 15,34 , and 25 , respectively, because they valued the diversity and quantity of the initial ideas. After going through the learning blocks, students had a shift in their beliefs about idea generation and also employed several ideation techniques. Students perceived idea generation as a phase that would encourage wild, impractical ideas, which helped them to minimize evaluation of early ideas. They aimed to generate a specific number of ideas and further used idea generation techniques such as Mind Mapping, Brainstorming, Design Heuristics, and Functional Decomposition to expand the possible number of concepts. For example, Brian used Mind Mapping to come up with subcomponent ideas and synthesized whole idea by combining various sub-components. Ideation techniques helped students to come up with a larger number of ideas that varied.

Currently, only a few engineering courses provide explicit instruction on promoting creativity in idea generation and problem solving [39-42]. A common instructional method in engineering to encourage creative problem solving is through open-ended projects, where students are encouraged to come up with a solution without a clearly defined target product. Students are encouraged to learn to think creatively through experience, rather than through direct instruction. The Center for Socially Engaged learning blocks offer a way for students to learn best practices for problem solving and incorporate explicit instruction to promote creativity.

Implications for engineering education

For educators in design and engineering, the Center for Socially Engaged Design learning blocks (csed.engin.umich.edu) can be used to supplement instruction on idea generation and development. University of Michigan has begun utilizing the learning blocks in the Mechanical Engineering Design courses and we are expanding the uses of the blocks to support co-curricular design teams and the multidisciplinary design program. Hundreds of students on campus can easily adopt the learning blocks, since they are self-paced, online modules. Faculty members who may not have the expertise nor time to cover idea generation and development in-depth can leverage the learning block material to teach students some of the best practices in design. Currently, the Center for Socially Engaged Design learning blocks are only available to students and faculty at the University of Michigan. In the future, we hope to disseminate this learning opportunity to both international and U.S. universities.

\section{Conclusion}

By incorporating systematic ways of educating engineering students to solve open-ended problems, we can more efficiently train engineers to face the challenges of the $21^{\text {st }}$ century. Idea generation and development are important skills for creating innovative concepts early in a design process. This study revealed some of the initial misconceptions of idea generation and development; students limited their solution space by coming up with false assumptions about the requirements and considered variations of existing solutions. Next, we designed and tested the impacts of learning blocks that provide online-learning modules with one-on-one coaching sessions. By going through the learning blocks, students adopted some of the best practices in 
ideation, such as not limiting ideas, and using tools that provided structured ways of generating and developing ideas.

\section{Acknowledgements}

We would like to thank all our participants who allowed us to study their practices. We would like to thank Hermione Li and Gabriella Rodriguez for their help in organizing and analyzing the data. This project is supported by NSF \# 1611687. 
Appendix A1. Problem statements provided to the students

\section{Low-Skill Snow Transporter Problem}

Today skis and snowboards are widely used as personal transportation tools on snow. But to be able to use them, a lot of skill and experience are required that a user cannot normally learn within one day. Moreover, skis and snowboards cannot run uphill easily. It would be better if there were other options of personal tools for transportation on snow, which still allowed the user to control direction and braking, but did not require much time to learn how to use.

Design a way for individuals without lots of skill and experience skiing or snowboarding to transport themselves on snow.

Develop solutions for this problem and select a final solution at the end. You can take as long as you need but spend a minimum of 1 hour to complete this task. If you need any resources, please let me know.

\section{One-Hand Opener for Lidded Food Containers Problem}

The local rehabilitation center helps to treat thousands of stroke patients each year. Many individuals who have had a stroke are unable to perform bilateral tasks, meaning they have limited or no use of one upper extremity (arm/shoulder). A common issue the hospital has observed with their stroke patients is in their ability to open jars and other lidded food containers. The ability to open lidded food containers is particularly important for patients who are living on their own, in which case they often don't have help around for even basic tasks. A solution to helping them open lidded food containers with one hand would go a long way in helping the patients to maintain their independence.

Design a way for individuals who have limited or no use of one upper extremity to open a lidded food container with one hand.

Develop solutions for this problem and select a final solution at the end. You can take as long as you need but spend a minimum of 1 hour to complete this task. If you need any resources, please let me know. 
Appendix A2. The full list of codes used in this study

\begin{tabular}{|l|l|}
\hline $\begin{array}{l}\text { Considered multiple ideas } \\
\text { (scarcity vs. fluency) }\end{array}$ & $\begin{array}{l}\text { Students considered less than 5 ideas (score 0), 5 but less than } 10 \\
\text { (score 1), 10 or greater (score 2). }\end{array}$ \\
\hline $\begin{array}{l}\text { Thought of existing } \\
\text { solutions }\end{array}$ & $\begin{array}{l}\text { Students thought or searched for existing products to generate } \\
\text { ideas. }\end{array}$ \\
\hline $\begin{array}{l}\text { Visualized/personalized the } \\
\text { scenario }\end{array}$ & $\begin{array}{l}\text { Students visualized themselves facing the problem in order to } \\
\text { get some inspiration to solve the problem. }\end{array}$ \\
\hline Idea fixation & Students are attached to a single idea or similar ideas. \\
\hline $\begin{array}{l}\text { Self - limiting behavior: a } \\
\text { solution does not fit the } \\
\text { problem scope }\end{array}$ & $\begin{array}{l}\text { Students disregarded ideas that they felt were not within the } \\
\text { scope of the problem statement. }\end{array}$ \\
\hline $\begin{array}{l}\text { Self - limiting behavior: a } \\
\text { solution is not feasible or } \\
\text { practical }\end{array}$ & $\begin{array}{l}\text { Students limited the solution space by placing practicality and } \\
\text { feasibility as a filter during idea generation. }\end{array}$ \\
\hline $\begin{array}{l}\text { Lack of knowledge or } \\
\text { expertise led to eliminating } \\
\text { ideas }\end{array}$ & $\begin{array}{l}\text { Students eliminated ideas due to their lack of } \\
\text { knowledge/expertise. }\end{array}$ \\
\hline $\begin{array}{l}\text { Iterated and combined } \\
\text { ideas }\end{array}$ & $\begin{array}{l}\text { Students iterated less than 5 ideas (score 0), 5 but less than 10 } \\
\text { (score 1), 10 or greater (score 2). }\end{array}$ \\
\hline $\begin{array}{l}\text { Techniques used (e.g. } \\
\text { Design Heuristics, } \\
\text { Morphological Analysis, } \\
\text { Brainstorming, } \\
\text { brainwriting, SCAMPER) }\end{array}$ & $\begin{array}{l}\text { Student did not use an ideation technique (score 0), used at least } \\
\text { one but did not use it clearly (score 1), intentionally used at least } \\
\text { one as recommended (score 2). }\end{array}$ \\
\hline $\begin{array}{l}\text { Fixated on quantitative } \\
\text { values during evaluation }\end{array}$ & $\begin{array}{l}\text { Students fixated on quantitative values produced using certain } \\
\text { evaluation/selection tools. }\end{array}$ \\
\hline $\begin{array}{l}\text { Balance benefits \& } \\
\text { tradeoffs }\end{array}$ & $\begin{array}{l}\text { Students balanced benefits and tradeoffs of each design and } \\
\text { decided the better design for which the pros outweighed the } \\
\text { cons. }\end{array}$ \\
\hline
\end{tabular}




\section{References}

[1] G. Clough, The Engineer of 2020: Visions of Engineering in the New Century. National Academy of Engineering. Washington DC: The National Academies Press, 2004.

[2] ABET Board of Directors, "Criteria for accrediting engineering programs, 2017-2018." 2016.

[3] D. R. Brophy, "Comparing the Attributes, Activities, and Performance of Divergent, Convergent, and Combination Thinkers," Creat. Res. J., vol. 13, no. 3-4, pp. 439-455, Oct. 2001.

[4] C. Nigel, "Design cognition: Results from protocol and other empirical studies of design activity," Des. Knowing Learn. Cogn. Des. Educ., vol. 7, pp. 9-103, 2001.

[5] S. Zenios et al., Biodesign: The Process of Innovating Medical Technologies, 1 edition. Cambridge, UK: Cambridge University Press, 2009.

[6] P. Rowe, Design thinking. Cambridge, MA: The MIT Press, 1987.

[7] D. G. Jansson and S. M. Smith, "Design fixation,” Des. Stud., vol. 12, no. 1, pp. 3-11, 1991.

[8] S. Isaksen and J. Gaulin, "A Reexamination of Brainstorming Research: Implications for Research and Practice," vol. 49, no. 4, pp. 315-329, 2005.

[9] D. P. Crismond and R. S. Adams, "The informed design teaching and learning matrix," J. Eng. Educ., vol. 101, no. 4, pp. 738-797, Oct. 2012.

[10] A. T. Purcell and J. S. Gero, "Design and other types of fixation," Des. Stud., vol. 17, no. 4, pp. 363-383, Oct. 1996.

[11] S. B. Niku, Creative Design of Products and Systems. Wiley, 2008.

[12] T. B. Ward, "Structured Imagination: the Role of Category Structure in Exemplar Generation," Cognit. Psychol., vol. 27, no. 1, pp. 1-40, Aug. 1994.

[13] G. Altshuller, 40 principles: TRIZ keys to technical innovation. Worcester, Mass.: Technical Innovation Center, Inc., 1997.

[14] J. L. Christian, S. R. Daly, S. Yilmaz, C. M. Seifert, and R. Gonzalez, "Design Heuristics to Support Two Modes of Idea Generation: Initiating Ideas and Transitioning Among Concepts," presented at the Annual Conference of American Society of Engineering Education, San Antonio, Texas, 2012.

[15] J. M. Kramer, S. R. Daly, S. Yilmaz, C. M. Seifert, and R. Gonzalez, "Investigating the Impacts of Design Heuristics on Idea Initiation and Development," Adv. Eng. Educ., vol. 4, no. 4, pp. 1-26, 2015.

[16] A. Ostrowski, J. W. Lee, S. Daly, A. Huang-Saad, and C. Seifert, "Design in Biomedical Engineering: Student Applications of Design Heuristics as a Tool for Idea Generation," in Proceedings of American Society for Engineering Education, Columbus, Ohio, 2017.

[17] J. W. Lee, A. K. Ostrowski, S. R. Daly, A. Y. Huang-Saad, and C. M. Seifert, "Extending Design Heuristics From Mechanical Engineering to a Biomedical Projects Course," in Proceedings of the ASME International Design Engineering Technical Conferences (IDETC), Cleveland, Ohio, 2017.

[18] A. F. Osborn, Applied imagination: Principles and procedures of creative problem-solving, 3rd Rev Edition. Buffalo, NY: Scribner, 1963.

[19] J. S. Linsey, "Design-by-analogy and representation of innovative engineering concept generation," PhD Dissertation, University of Texas, Austin, TX, 2007.

[20] S. Yilmaz, S. R. Daly, C. M. Seifert, and R. Gonzalez, "Evidence-based design heuristics for idea generation,” Des. Stud., vol. 46, pp. 95-124, Sep. 2016. 
[21] E. de Bono, New think: The use of lateral thinking in the generation of new ideas. New York: Basic Books, 1968.

[22] M. Allen, Morphological Creativity: The Miracle of Your Hidden Brain Power. New Jersey: Prentice-Hall, 1962.

[23] R. Eberle, SCAMPER. Waco, TX: Prufrock, 1995.

[24] J. Kim and D. Wilemon, "Focusing the fuzzy front-end in new product development.," $R D$ Manag., vol. 32, no. 4, pp. 269-279, 2002.

[25] N. Cross, Engineering Design Methods: Strategies for Product Design, 4th ed. West Sussex, England: Wiley, 2008.

[26] C. J. Atman, J. R. Chimka, K. M. Bursic, and H. L. Nachtmann, “A comparison of freshman and senior engineering design processes,” Des. Stud., vol. 20, no. 2, pp. 131-152, Mar. 1999.

[27] E. Starkey, C. A. Toh, and S. R. Miller, "Abandoning creativity: The evolution of creative ideas in engineering design course projects," Des. Stud., vol. 47, pp. 47-72, Nov. 2016.

[28] D. Grasso, M. B. Burkins, J. J. Helble, and D. Martinelli, "Dispelling the Myths of Holistic Engineering," in Holistic Engineering Education, NY: Springer, 2010, pp. 159-165.

[29] S. R. Hiltz and B. Wellman, "Asynchronous Learning Networks As a Virtual Classroom," Commun ACM, vol. 40, no. 9, pp. 44-49, Sep. 1997.

[30] B. Wadsworth, Piaget's theory of cognitive and affective development: Foundations of constructivism, vol. 5th ed. White Plains, NY: Longman Publishing, 1996.

[31] F. Mayadas, "Asynchronous Learning Networks: A Sloan Foundation Perspective," J. Asynchronous Learn. Netw., vol. 1, no. 1, pp. 1-16, 1997.

[32] M. Prince, "Does Active Learning Work? A Review of the Research," J. Eng. Educ., vol. 93, no. 3, pp. 223-231, Jul. 2004.

[33] K. A. Smith, S. D. Sheppard, D. W. Johnson, and R. T. Johnson, "Pedagogies of Engagement: Classroom-Based Practices," J. Eng. Educ., vol. 94, no. 1, pp. 87-101, Jan. 2005.

[34] M. R. Young, S. R. Daly, S. L. Hoffman, K. H. Sienko, and M. A. Gilleran, "Assessment of a Novel Learning Block Model for Engineering Design Skill Development: A Case Example for Engineering Design Interviewing," in Proceedings of American Society for Engineering Education, Columbus, OH, 2017.

[35] A. Rechkemmer et al., "Examining the Effect of a Paradigm-Relatedness Problem-Framing Tool on Idea Generation," in Proceedings of American Society for Engineering Education, Columbus, OH, 2017.

[36] D. C. Sevier, K. Jablokow, S. McKilligan, S. R. Daly, I. N. Baker, and E. M. Silk, "Towards the Development of an Elaboration Metric for Concept Sketches," in Proceedings of the ASME International Design Engineering Technical Conferences (IDETC), Cleveland, Ohio, 2017.

[37] M. W. Van Someren, Y. F. Barnard, and J. A. C. Sandberg, The think aloud method: a practical approach to modelling cognitive processes, Academic Press, 1994.

[38] K. Louise Barriball and A. While, "Collecting data using a semi-structured interview: a discussion paper," J. Adv. Nurs., vol. 19, no. 2, pp. 328-335, Feb. 1994.

[39] S. Hutchinson and H. Wilson, "Validity Threats in Scheduled Semistructured Research Interviews," Nurs. Res., vol. 41, no. 2, pp. 117-119, 1992.

[40] K. Bailey, Methods of Social Research, 4th Edition. New York, NY: The Free Press, 1994.

[41] R. Gordon, Interviewing: Strategy, Techniques and Tactics. Illinois: Dorsey Press, 1975. 
[42] S. Jacob and S. Furgerson, "Writing Interview Protocols and Conducting Interviews: Tips for Students New to the Field of Qualitative Research," Qual. Rep., vol. 17, no. 42, pp. 110, Oct. 2012.

[43] M. Patton, Qualitative Research \& Evaluation Methods: Integrating Theory and Practice, 4th ed. Thousand Oaks, CA: SAGE Publications, 2015.

[44] J. W. Creswell, Research Design: Qualitative, Quantitative, and Mixed Methods Approaches. SAGE Publications, 2013.

[45] J. Osborne, Best practices in quantitative methods. Thousand Oaks, CA: Sage, 2008.

[46] C. Charyton and J. A. Merrill, "Assessing general creativity and creative engineering design in first year engineering students," J. Eng. Educ., vol. 98, no. 2, pp. 145-156, 2009.

[47] S. Dewulf and C. Baillie, Case: Creativity in Art, Science and Engineering : how to Foster Creativity. Great Britain Department for Education and Employment, 1999.

[48] K. Kazerounian and S. Foley, "Barriers to Creativity in Engineering Education: A Study of Instructors and Students Perceptions," J. Mech. Des., vol. 129, no. 7, pp. 761-768, Feb. 2007.

[49] W. B. Stouffer, J. S. Russell, and M. G. Oliva, "Making the strange familiar: Creativity and the future of engineering education," in Proceedings American Society for Engineering Education, Salt Lake City, UT, 2004. 